\title{
A conceptual model of referee efficacy
}

\author{
Félix Guillén ${ }^{1}$ and Deborah L. Feltz ${ }^{2 *}$ \\ Department of Physical Education and Sport, University of Las Palmas de Gran Canaria, Las Palmas, Grand Canary Island, Spain \\ 2 Department of Kinesiology, Michigan State University, East Lansing, MI, USA
}

\author{
Edited by: \\ Ernst-Joachim Hossner, University of \\ Bern, Switzerland \\ Reviewed by: \\ lain Greenlees, University of \\ Chichester, UK \\ Bob Grove, University of Western \\ Australia, Australia \\ *Correspondence: \\ Deborah L. Feltz, Department of \\ Kinesiology, Michigan State University, \\ I.M. Sports-Circle, East Lansing, MI \\ 48824, USA. \\ e-mail:dfeltz@msu.edu
}

This paper presents a conceptual model of referee efficacy, defines the concept, proposes sources of referee specific efficacy information, and suggests consequences of having high or low referee efficacy. Referee efficacy is defined as the extent to which referees believe they have the capacity to perform successfully in their job. Referee efficacy beliefs are hypothesized to be influenced by mastery experiences, referee knowledge/education, support from significant others, physical/mental preparedness, environmental comfort, and perceived anxiety. In turn, referee efficacy beliefs are hypothesized to influence referee performance, referee stress, athlete rule violations, athlete satisfaction, and co-referee satisfaction.

Keywords: referee behavior, referee confidence, sports officiating, umpires
Sport referees have a challenging job, due to the many aspects of a game/match that they must take into account, the speed and complexity of the decisions they must make, the repercussions their actions have, the number of people involved in the match, and often the hostile nature of spectators at the sport event. They are required to perform many different tasks, including evaluating and judging the actions that take place during the match, making fast decisions, managing the game, paying attention to multiple aspects of the game, keeping order, and solving disputes (Tuero et al., 2002). All this not only makes the job very complex, but also makes it easy to commit mistakes. As a consequence of the constant decision-making, the subjectivity of referees when assessing actions, and the mistakes they may make, they are often criticized for their decisions (Anderson and Pierce, 2009). This criticism may come from the players and the coaches as well as sports managers, fans (Rainey et al., 1990; VanYperen, 1998) or the sports media (Guillen, 2006).

Referee mistakes can have devastating consequences from an economical and social perspective for clubs and fans, and also for athletes and teams (Guillen, 2003a). A example is the recent self-admitted mistake by major league baseball umpire, Jim Joyce (June 2, 2010). Joyce called a player safe at first base and took away Detroit Tiger pitcher, Armando Galarraga's, perfect game. Joyce was described as looking and sounding distraught (Associated Press, June 3,2010). The officiating task itself and the possible mistakes inherent in it can lead to a loss of confidence, high anxiety, and increased stress levels in referees (Taylor and Daniel, 1987; Anshel and Weinberg, 1995; Rainey, 1995a,b) and, consequently, lead to the more and more frequent referee dropout (Balch and Scott, 2007; Titlebaum et al., 2009). These anxiety levels and their causes are similar across different sports officiating contexts (e.g., soccer, basketball, volleyball). The stress of officiating has been shown to negatively influence sports officials' mental health, attentional focus, performance, satisfaction with their profession, and dropout intentions (Taylor et al., 1990; Goldsmith and Williams, 1992; Guillen and Bara, 2004).
One psychological mechanism that has been shown to mitigate stress and anxiety related to performance is one's sense of self-efficacy (Bandura, 1997). According to Bandura, self-efficacy is defined as the strength of an individual's conviction that he or she can successfully execute a behavior required to achieve a certain outcome. Such perceptions are predicted to influence task choices, effort expenditure, and resilience to failure. According to selfefficacy theory, perceived self-efficacy influences stress and anxiety through one's beliefs about personal control of actions, thoughts, and affect (Bandura, 1997). Those who are confident in their abilities focus on the challenge and what they need to do to accomplish their task and worry less about making mistakes or the pressure of the situation. Reciprocally, Bandura $(1977,1997)$ also views anxiety as a source of efficacy information. Those who worry about their upcoming task and pressure will have more doubts about their capability than those who feel less anxious. Bandura's conceptualization of self-efficacy's relationship to behavior is dependent, in part, on people having sufficient incentives to act on their efficacy beliefs and possessing the requisite skills.

Within the domain of sport psychology, self-efficacy has been extensively studied as a cognitive variable related to sport-achievement strivings (Feltz et al., 2008). Generally, studies on self-efficacy in sport (where sufficient incentives to perform and requisite skills exist) have found a positive relationship between one's efficacy expectations and performance (Moritz et al., 2000) and a negative relationship between efficacy beliefs and anxiety (Haney and Long, 1995; Cartoni et al., 2005). Additionally, studies have supported a strong relationship between self-efficacy and work-related performance (Stajkovic and Luthans, 1998).

While such studies have corroborated Bandura's $(1977,1997)$ suppositions regarding the impact of self-efficacy on athletic and work performance, no sport empiricist to-date has attempted to extend this area of research to include referee efficacy. We define referee efficacy, which we term refficacy for convenience, as the extent to which referees believe they have the capacity to perform successfully in their job. As in athletic and work-related performance, 
one would expect a positive relationship between refficacy beliefs and performance and a negative relationship between refficacy and performance anxiety and stress. Given that referees have to pass an exam to be allowed to perform and choose to accept an assignment, one can assume they have the adequate incentive to perform and the requisite skills. Highly efficacious referees should be more accurate in their decisions, more effective in their performance, more committed to their profession, have more respect from coaches, administrators, and other officials and be able to avoid the stress that officiating generates. In fact, the aspect that interests and worries referees the most is self-confidence, as some empirical studies have confirmed (Ittenbach and Eller, 1988; Guillen and Jimenez, 2001; Guillen, 2003b). This article presents the concept of refficacy and proposes a model that can be used to examine the construct and its sources and outcomes.

\section{CONCEPTUAL FRAMEWORK}

Although researchers have developed conceptual frameworks for efficacy beliefs in various work performance contexts, such as teacher efficacy (Gibson and Dembo, 1984), managerial efficacy (Wood et al., 1990), and coaching efficacy (Feltz et al., 1999), those frameworks are not suitable for studying refficacy. Refficacy has a unique context that involves split-second decision-making with an ad hoc team of other referees that takes place in front of an audience (often unfriendly). Thus, there may be dimensions to refficacy and sources of efficacy information that are unique to efficacy beliefs and performance in this context.

Using Bandura's $(1977,1997)$ conceptualization of self-efficacy, we propose a model of refficacy that includes referee specific sources of efficacy information as well as the effects or outcomes of refficacy. This model is illustrated in Figure 1. Key aspects of refficacy were defined as a result of a focus group of nine male referees from the Midwestern region of the United States of America who had varying levels of soccer referee experience and the first author's personal experience as a soccer referee. The referees ranged in age from 21 to 55 years $(M=30.11$; $\mathrm{SD}=13.38$ ), and United States Soccer Federation grades of 8 (i.e., generally assigned youth matches) to 5 (i.e., highest level of competition within a State). Before conducting the focus group, permission was obtained from the institutional review board.

The aim of the focus group was not to conduct a research study but rather to seek input in developing our model. Although previous studies have indicated some of the characteristics that influence self-efficacy in a sports context, we wanted to obtain a description of the key dimensions of refficacy, the sources of refficacy from referees' point of view, and the way in which one's refficacy influences performance and other outcomes. After appropriate introductions, we provided our definition of refficacy. We then asked the participants, "What do you think are the keys areas of refficacy needed to perform your referee job?" Next we asked about the sources of their efficacy. "What influences your efficacy beliefs about officiating?; what gives you more confidence when officiating?; what makes you lose confidence when you officiate?" Lastly, we asked, "How does your level of refficacy influence your behavior/thoughts as an official; others' behavior?"

The 2-h focus group session was conducted with two moderators. One of the moderators was one of the researchers; the other moderator was a referee who offered to collaborate during the session(s) and also when contacting participants; and the observer was the other researcher, who observed the whole session and took notes of the comments made by participants.

\section{DIMENSIONS OF REFFICACY}

From discussions with the referees, we arrived at the following six key confidence components for officiating success: game knowledge, decision-making skills, psychological skills, strategic skills, communication/control of game, and physical fitness.

\section{GAME KNOWLEDGE}

In the many training handbooks for referees and judges published by different referee organizations (Greensted, 1997; Gama et al., 1998), there is an emphasis on physical, technical, and tactical aspects. Likewise, scientific research has insisted on a referee's need for adequate knowledge of the game (Weinberg and Richardson, 1990; Davis, 1996; Perlmuter et al., 1997; Grunska, 1999). In fact, referees are aware that a thorough knowledge of the game or sports in which they are officiating is essential (Ittenbach and Eller, 1988). Focus group referees mentioned knowing the rules of their sport, understanding proper officiating mechanics, and understanding the basic strategy of the game as examples of game knowledge.

\section{STRATEGIC SKILLS}

Strategic performance for referees is a group of actions taken to make the right interpretations of the game and its rules. These strategic skills imply knowing where to stand on the field/court and how to move, making the correct gestures each time and anticipating actions. Focus group members mentioned staying up with the play, being at the proper angles for decisions, and anticipating game actions as examples of strategic performance. The importance of these skills has been confirmed in other studies (Guillen and Jimenez, 2001; Ste-Marie, 2003).

\section{DECISION-MAKING SKILLS}

The speed and accuracy in decision-making is cited as one of the most important aspects of referee performance (Helsen and Bultynck, 2004; MacMahon et al., 2007). Focus group members mentioned making critical decisions during competitions, demonstrating accurate judgments, and being firm in one's decisions as examples of decision-making skills.

\section{PSYCHOLOGICAL SKILLS}

Just as athletes need psychological skills to perform successfully (Crust, 2007), so do referees (Weinberg and Richardson, 1990; Kaissidis-Rodafinos et al., 1997; Guillen, 2006). Officials need to be able to focus their attention and concentration, stay cool under pressure, cope with mistakes and adverse situations, and set realistic goals. Focus group members mentioned concentrating well enough to be successful, recovering from making a bad call, demonstrating poise under pressure, and achieving one's professional goals as examples of the psychological skills needed in officiating.

\section{COMMUNICATION/CONTROL OF GAME}

Grunska (1999) discusses the official's ability to communicate effectively with participants and control game situations as instrumental to being a successful official. Our focus group members agreed. 


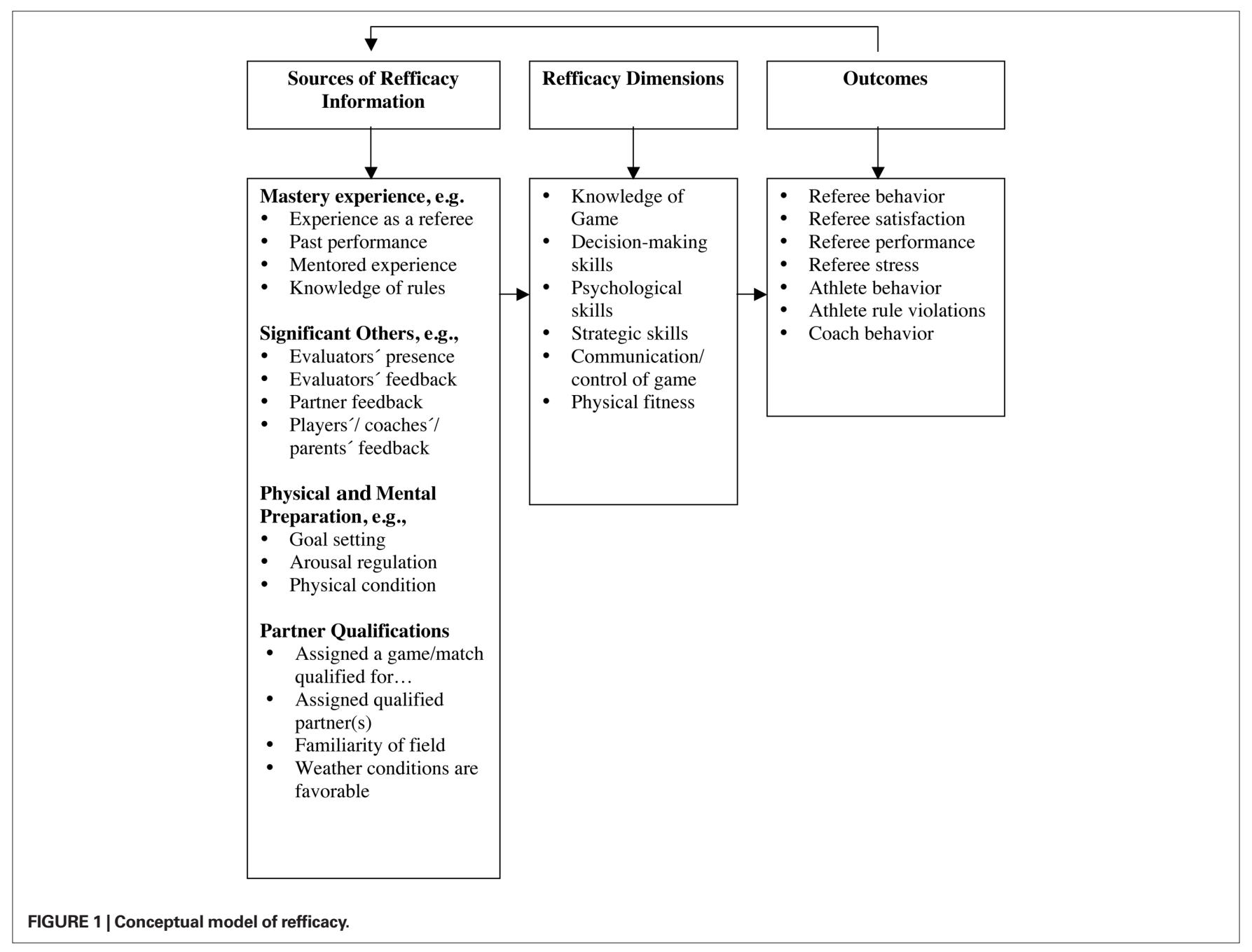

They mentioned communicating effectively with players, coaches, and co-officials as examples of communication. They also saw effective communication as relating to maintaining control of the game and resolving disputes.

\section{PHYSICAL FITNESS}

In most sports, referees engage in a lot of physical exercise. In some cases they even cover several kilometers in a game, so physical fitness is an essential aspect in this job. The relevance of physical fitness has been highlighted by sports officials (Villalobos et al., 2002), and also by many international sports federations through their regulations and the documents they provide to their referees (Davis, 1996). Our focus group members mentioned being in good physical condition and staying up with the play as examples of physical fitness for officiating.

\section{SOURCES OF REFFICACY}

The sources of refficacy information were derived from Bandura's $(1977,1997)$ proposed sources of efficacy information, the Sources of Sport Confidence Questionnaire (SSCQ; Vealey et al., 1998), and input from the focus group of referees. As illustrated in Figure 1, we propose that dimensions of refficacy are influenced by one's mastery experience (e.g., years of referee experience, past performance, mentored experience, and knowledge of the rules). This is based on Bandura's $(1977,1997)$ category of performance accomplishments. According to Bandura, this category of information is hypothesized as the most dependable for forming an efficacy judgment and is hypothesized to be the strongest predictor of refficacy.

A second source of refficacy information is based on perceived level of support/non-support from significant others (e.g., players'/coaches'/parents' feedback, peer/partner feedback, evaluator's feedback, and social comparison with other referees). This source of information is similar to Bandura's $(1977,1997)$ verbal persuasion category of efficacy information and also has been identified in Vealey et al.'s (1998) SSCQ and Feltz et al.'s (1999) model of coaching efficacy. Officiating often lends itself to feedback/criticism from players and coaches during a match. Partner feedback also plays a significant role; other referees can offer qualified assessment. Anonymous evaluators from the officials' association also provide valuable information and rankings for officials.

The third category, "Physical and Mental preparation," involves feeling physically and mentally prepared for optimal performance and is based on Vealey et al.'s (1998) SSCQ. This includes establishing goals for a match, regulating arousal, employing 
self-talk, visualizing good performance, and believing one is ready to give maximum effort in officiating. This category also includes anxiety, and thus, is also similar to Bandura's (1977, 1997) emotional arousal source of efficacy information. Officials who do not feel that they can regulate their emotional arousal before a game will feel unprepared emotionally, which can lead to feelings of anxiety.

The last category, "Partner Qualifications" [e.g., assigned a game/ match for which I feel qualified; assigned a qualified partner(s); familiar with partner(s); confidence in partner(s)' ability; familiarity of field; weather conditions are favorable] is composed of aspects that we believe affect self-efficacy, and is based on Vealey et al.'s (1998) Environmental Comfort subscale in the SSCQ. Our personal experience working with referees, the results in the focus group, and the literature of the field confirm that referees have a preference for performing in certain games and/or places (e.g., officiating a match at home or away: Boyko et al., 2007) and facilities with specific characteristics (e.g., proximity of the audience to the field; stadiums with many or few spectators) and with certain fans (e.g., certain audiences are louder or more aggressive than others; Balmer et al., 2007).

\section{OUTCOMES OF REFFICACY}

In terms of outcomes of refficacy beliefs, based on Bandura's (1977, 1997) theory, research from coaching and managerial efficacy (e.g., Ashton and Webb, 1986; Wood et al., 1990; Feltz et al., 1999), and research on decision-making performance and self-efficacy in sport (e.g., Hepler and Chase, 2008), we propose that refficacy beliefs will have an influence on one's decision-making performance, referee stress, athlete rule violations, athlete satisfaction, coach behavior, and co-referee satisfaction.

Research has found that efficacy beliefs are positively related to decision-making performance in various settings, including business (Bandura and Wood, 1989; Wood and Bandura, 1989) and sport (Tenenbaum et al., 1996; Hepler and Chase, 2008). Hepler and Chase (2008) found that self-efficacy was a positive and significant predictor of decision-making performance (speed and accuracy) in a simulated baseball-fielding task.

High efficacy referees are hypothesized to demonstrate faster and more accurate decisions, have greater physical fitness, have athletes and coaches report more satisfaction with referee performance,

\section{REFERENCES}

Anderson, K. J., and Pierce, D. A. (2009). Officiating bias: the effect of foul differential on foul calls in NCAA basketball. J. Sports Sci. 27, 687-694.

Anshel, M., and Weinberg, R. (1995). Sources of acute stress in American and Australian basketball referees. J. Appl. Sport Psychol. 7, 11-22.

Ashton, P. T., and Webb, R. B. (1986). Making a Difference: Teachers' Sense of Efficacy and Student Achievement. New York: Longman.

Balch, M. J., and Scott, D. (2007). Contrary to popular belief, referees are people too! Personality and perceptions of officials. J. Sport Behav. 30, 3-20.
Balmer, N. J., Nevill, A. M., Lane, A. M., Ward, P., Williams, A. M., and Fairclough, S. H. (2007). Influence of crowd noise on soccer refereeing consistency in soccer. J. Sport Behav. 30, 130-145.

Bandura, A. (1977). Self-efficacy: toward a unifying theory of behavioral change. Psychol. Rev. 84, 191-215.

Bandura, A. (1997). Self-Efficacy: The Exercise of Control. New York: Freeman.

Bandura,A., and Wood, R.E. (1989).Effect of perceived controllability and performance standards on self-regulation of complex decision-making. J. Pers. Soc. Psychol. 56, 805-814.

have co-referees who report more satisfaction in working with their counterpart referee, report lower referee stress, and have fewer athlete rule violations than low efficacy referees. Further, the specific dimensions of refficacy should link to specific outcomes. For instance, referees who are high in their efficacy for knowledge of the rules and decision-making should display faster and more accurate decisions. Referees who are high in their fitness should perform better on fitness measures.

Based on Bandura's $(1977,1997)$ theory, which posits a reciprocal relationship between efficacy beliefs and performance, the outcomes in our model are proposed to influence future refficacy beliefs. For instance referee performance becomes past performance in the future and a future source of efficacy information.

\section{DISCUSSION}

Due to the special characteristics of the officiating task, the models that have been used to study the efficacy beliefs in managers, teachers, and coaches cannot be used here. Among the reasons for this, we find the peculiarities of the officiating task itself, the fact that referees are observed by hundreds or thousands of fans in each match/game and that there are many people - athletes, coaches, managers, fans - trying to exert an influence on each of the referee's decision. This complexity of the officiating task has led us to design a new model which allows us to include the different aspects that play a determining role for the referee.

We consider our model of refficacy to be a preliminary model that probably contains fewer sources, dimensions, and outcomes of refficacy than may actually exist. The model offers a starting framework, however, for research on the confidence-related aspects of sports officiating. Future research can provide novel corroborations or falsifications to extend and or tighten the model (Feltz, 1987). We realize that our initial conceptualization has limitations. Our focus group consisted of male-only soccer referees. Other types of team-sports officials may have provided different sources, dimensions, and outcomes to the refficacy model. In addition, if one is conducting focus group research, one typically utilizes several groups and/or several sessions until a saturation point is reached. Given that multiple groups/sessions were not used here, there may have been additional information to add to the model. We invite other scholars to test and extend this model and begin developing an empirical base of research on refficacy.

Boyko, R. H., Boyko, A. R., and Boyko, M. G. (2007). Referee bias contributes to home advantage in English premiership football. J. Sports Sci. 25, 1185-1194.

Cartoni, A. C., Minganti, C., and Zelli, A. (2005). Gender, age, and professionallevel differences in the psychological correlates of fear of injury in Italian gymnasts. J. Sport Behav. 28, 3-17.

Crust, L. (2007). Mental toughness in sport: a review. Int. J. Sport Exerc. Psychol. 5, 270-290.

Davis, K. L. (1996). The Arts of Sports Officiating. Needham Heights, MA: Allyn \& Bacon.

Feltz, D. L. (1987). Advancing knowledge in sport psychology: strategies for expanding our conceptual frameworks. Quest 39, 243-254.

Feltz, D. L., Chase, M. A., Moritz, S. E., and Sullivan, P. J. (1999). A conceptual model of coaching efficacy: preliminary investigation and instrument development. J. Educ. Psychol. 91, 675-776.

Feltz,D.L., Short, S., and Sullivan,P.(2008). Self-Efficacy in Sport. Champaigns, IL: Human Kinetics.

Gama,A., Corte,A., Monge, D. M.,Araujo, D., Ramos, J. P., Horta, L., Marivoet, S., Serpa, S., Lima, T., Weinberg, R., and Richardson, P. (1998). Manual do arbitro [Handbook for Referees]. Lisbon: Secretaria de Estado do Desporto. 
Gibson,S., and Dembo, M. (1984). Teacher efficacy: a construct validation. J. Educ. Psychol. 76, 569-582.

Goldsmith, P. A., and Williams, J. (1992). Perceived stressors for football and volleyball officials from three rating levels. J. Sport Behav. 15, 106-118.

Greensted, R. (1997). The RFU Rugby Union. Referee's Manual. London: A \& C Black.

Grunska, J. (1999). Successful Sport Officiating. Champaign, IL: Human Kinetics.

Guillen, F. (2003a). "Panorama actual en el estudio del arbitraje y el juicio deportivo desde una perspectiva psicológica [Current overview of the study of refereeing and sports judging from a psychological approach]," in Psicología del Arbitraje y el Juicio Deportivo, ed. F. Guillén (Barcelona: Inde), 7-24.

Guillen, F. (2003b). "Características de eficacia requeridas en los árbitros y jueces deportivos [Effectiveness characteristics required from referees and sports judges]," in Psicología del Arbitraje y el Juicio Deportivo, ed. F. Guillén (Barcelona: Inde), 55-75.

Guillen, F. (2006). "La psicología del arbitraje y del juicio deportivo [The psychology of refereeing and judging in sports]," in Deporte y Psicología, eds. E. Garcés de los Fayos, A. Olmedilla, and P. Jara (Murcia: Diego Marín), 667-684.

Guillen, F., and Bara, M. (2004). La ansiedad rasgo y estado entre árbitros de diferentes modalidades deportivasy no árbitros [Trait and state anxiety among referees of different sports and nonreferees]. Revista de Entrenamiento Deportivo 18, 19-25.

Guillen, F., and Jimenez, H. (2001). Características deseables en el arbitraje y el juicio deportivo [The ideal characteristics of refereeing and sports judging]. Revista de Psicología del Deporte 10, 23-34.
Haney, C. J., and Long, B. C. (1995). Coping effectiveness: a path analysis of self-efficacy, control, coping, and performance in sport competitions. J. Appl. Soc. Psychol. 25, 1726-1746.

Helsen, W., and Bultynck, J. B. (2004). Physical and perceptual-cognitive demands of top-class refereeing in association football. J. Sports Sci. 22, 179-189.

Hepler, T. J., and Chase, M. A. (2008). Relationship between decisionmaking, task self-efficacy, and the performance of a sport skill. J. Sports Sci. 26, 603-610.

Ittenbach, R. F., and Eller, B. F. (1988). A personality profile of southeastern conference football officials. J. Sport Behav. 11, 115-125.

Kaissidis-Rodafinos, A., Anshel, M. H., and Porter, A. (1997). Personal and situational factors that predict coping strategies for acute stress among basketball referees. J. Sports Sci. 15, 427-436.

MacMahon, C., Helsen, W. F., Starkes, J. L., and Weston, M. (2007). Decisionmaking skills and deliberate practice in elite association football referees. $J$. Sports Sci. 25, 65-78.

Moritz, S. E., Feltz, D. L., Fahrbach, K. R., and Mack, D. E. (2000). The relation of self-efficacy measures to sport performance: a meta-analytic review. Res. Q. Exerc. Sport 71, 280-294.

Perlmuter, R. E., Richards, F. A., Dreimiller, D., Dreimiller, J., and Hoyt, C. L. (1997). Sports Officiating: Career Handbook. Cleveland, OH: LR Publishing Company.

Rainey, D. W. (1995a). Sources of stress among baseball and soft-ball umpired. J. Appl. Sport Psychol. 7, 1-10.

Rainey, D. W. (1995b). Stress, burnout and intention to terminate among umpires. J. Sport Behav. 18, 312-323.

Rainey, D. W., Schweickert, G., Granito, V., and Pullella, J. (1990). Fan's evaluations of major league baseball umpires' performances and perceptions of appropriate behavior toward umpired. J. Sport Behav. 13, 122-129.

Stajkovic, A., and Luthans, F. (1998). Selfefficacy and work-related performance: a meta-analysis. Psychol. Bull. $124,240-261$.

Ste-Marie, D. (2003). Memory biases in gymnastic judging: differential effects of surface feature changes. Appl. Cogn. Psychol. 17, 733-751.

Taylor, A., and Daniel, J. (1987). "Sources of stress in soccer officiating: an empirical study," in Science and Football: Proceedings of the First World Congress of Science and Football, eds T. Reilly, A. Lees, K. Davids, and W. J. Murphy (London: E \& F. N. Spon), 538-544.

Taylor, A., Daniel, J., Leith, L., and Burke, R. J. (1990). Perceived stress, psychological burnout and paths to turnover intentions among sport officials. J. Appl. Sport Psychol. 2, 84-97.

Tenenbaum, G., Levy-Kolker, N., Sade, S., Lieberman, D. G., and Lidor, R. (1996). Anticipation and confidence of decisions related to skill performance. Int. J. Sport Psychol. 27, 293-307.

Titlebaum, P. J., Haberlin, N., and Titlebaum, G. (2009). Recruitment and retention of sports officials. Recreat. Sports J. 33, 102-108.

Tuero, C., Tabernero, B., Marquez, S., and Guillen, F. (2002). Análisis de los factores que influyen en la práctica del arbitraje [Analysis of the factors affecting the practice of refereeing]. Sociedade Capixaba de Psicologia do Esporte 1, 7-16.

VanYperen, N.W. (1998). Predicting stay/ leave behavior among volleyball referees. Sport Psychol. 72, 427-439.

Vealey, R. S., Hayashi, S. W., GarnerHolman, G., and Giacobbi, P. (1998). Source of Sport confidence: conceptualization and instrument development. J. Sport Exerc. Psychol. 20, 54-80.

Villalobos, D., Ugarte, O., and Guillen, F. (2002). Situación actual y expectativas del árbitro de fútbol costarricense, de primera y segunda división [Current situation and expectations of the Costa Rican soccer referee of first and second divisions]. Kinesis 33, 17-24.

Weinberg, R. S., and Richardson, P. A. (1990). Psychology of Officiating. Champaign, IL: Leisure Press.

Wood, R. E., and Bandura, A. (1989). Impact of conceptions of ability on self-regulatory mechanisms and complex decision making. J. Pers. Soc. Psychol. 56, 407-415.

Wood, R. E., Bandura, A., and Bailey, T. (1990). Mechanisms governing performance in complex decision-making environments. Organ. Behav. Hum. Decis. Process 46, 181-201.

Conflict of Interest Statement: The authors declare that the research was conducted in the absence of any commercial or financial relationships that could be construed as a potential conflict of interest.

Received: 27 October 2010; paper pending published: 06 December 2010; accepted: 07 February 2011; published online: 18 February 2011.

Citation: Guillén F and Feltz DL (2011) A conceptual model of referee efficacy. Front. Psychology 2:25. doi: 10.3389/ fpsyg.2011.00025

This article was submitted to Frontiers in Movement Science and Sport Psychology, a specialty of Frontiers in Psychology.

Copyright (C) 2011 Guillén and Feltz. This is an open-access article subject to an exclusive license agreement between the authors and Frontiers Media SA, which permits unrestricted use, distribution, and reproduction in any medium, provided the original authors and source are credited. 